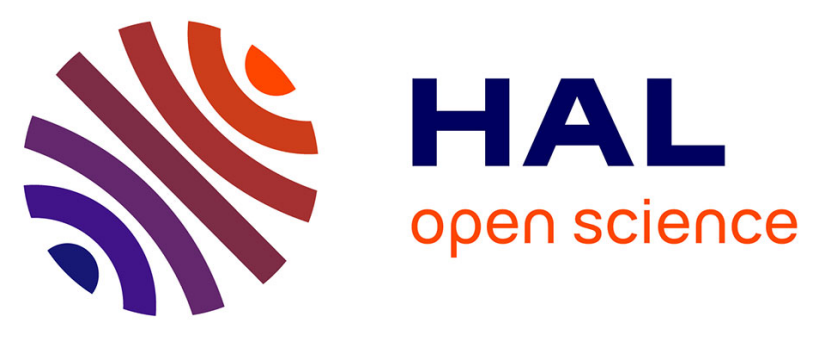

\title{
Man-Machine Interaction Improvement by Means of Automatic Human Personality Identification
}

\author{
Ryszard Tadeusiewicz, Adrian Horzyk
}

\section{To cite this version:}

Ryszard Tadeusiewicz, Adrian Horzyk. Man-Machine Interaction Improvement by Means of Automatic Human Personality Identification. 13th IFIP International Conference on Computer Information Systems and Industrial Management (CISIM), Nov 2014, Ho Chi Minh City, Vietnam. pp.278-289, 10.1007/978-3-662-45237-0_27. hal-01405598

\section{HAL Id: hal-01405598 \\ https://hal.inria.fr/hal-01405598}

Submitted on 30 Nov 2016

HAL is a multi-disciplinary open access archive for the deposit and dissemination of scientific research documents, whether they are published or not. The documents may come from teaching and research institutions in France or abroad, or from public or private research centers.
L'archive ouverte pluridisciplinaire HAL, est destinée au dépôt et à la diffusion de documents scientifiques de niveau recherche, publiés ou non, émanant des établissements d'enseignement et de recherche français ou étrangers, des laboratoires publics ou privés.

\section{(c)(1)}

Distributed under a Creative Commons Attribution| 4.0 International License 


\title{
Man-Machine Interaction Improvement by Means of Automatic Human Personality Identification
}

\author{
Ryszard Tadeusiewicz and Adrian Horzyk \\ AGH University of Science and Technology, \\ Department of Automatics and Biomedical Engineering, \\ \{rtad, horzyk\}@agh.edu.pl
}

\begin{abstract}
Creators of numerous information systems frequently concentrate on the semantic aspects of communication during planning and forming of man-machine interactions. Meanwhile emotions and adequate reactions to needs play equally essential role as rational reasoning when intelligence of a partner is judged. Intelligent behaviours and reactions usually deliberately affect the partner's needs. Therefore a computer could be accepted as an intelligent partner if it considers human needs affecting emotions. This paper presents a new method of automatic human needs recognition based on the extended personality typology that is described using characteristic verbal expressions. It enables to perform automatic passive classification of personality by means of psycholinguistic analysis during typical merit man-machine communication.
\end{abstract}

Keywords: man-machine interaction; natural language interfaces; emotional factor; psychological issues; human personality recognition.

\section{Introduction to recognition of personality needs}

Communication with machines has become daily and common. It takes place through various man-machine interfaces that use menus, dialog boxes, or form elements. Sometimes there are used more advanced interfaces that use voice recognition, synthesis, or natural language analysis [3]. Computers are used to deliver, forward, process, and store various kinds of data that have information value for people and even for computers which change their behaviour and state after the read and processed data [5]. Nowadays we expect that computers will act and react in more human and intelligent way. 'Intelligent' means not only accurate, precise, efficient, and deliberately using knowledge that is based on the objectives but also taking into account the needs of interacting partners $[3,7,9,14]$. This paper focuses on recognition of human needs using extended personality typology which describes groups of needs associated with various personality types. These types can be recognized by means of psycholinguistic analysis of texts written by any analysed person, during chats or observation of actions on websites. The main challenge is to recognize individual human needs 
and adjust machine reactions to them to make the man-machine interaction pleasant, satisfactory, appropriate, and deliberate in view of his or her needs, so that modern intelligent machines could cooperate with people more efficiently.

Needs are not easy to identify when talking with another person, because people rarely talk about their needs directly. Much appropriate and fast solution can be delivered by automatic analysing of their personality, because it allows to easy identify many groups of needs, behaviours, likes, and dislikes. This paper introduces the extended personality typology in order to relate them to likes and dislikes that determinate predictable actions and reactions that can be influenced by changing the impact of machines on people.

Various needs of personality incline or avoid us to do something. They are also strictly associated with pleasure and satisfaction that can be achieved. People usually choose satisfaction or pleasure and avoid pain or problems, however, often the fulfilment of a given group of needs stands in contradiction with the others. Because some personality types are usually stronger than others, estimating their strength usually enables us to expect actions and predict reactions of individuals. It also can help machines to satisfy people when they are talking with machines capable to adjust interaction accordingly to the recognized needs of human partners. Similar personalities usually cooperate easier, because they mutually share pleasure. Different personalities can complement each other, although the cooperation cannot be easy.

As an alternative to the other known typologies [6,8], the introduced expanded character typology describes 10 extrovert and 10 introvert types (Fig. 1). Inborn character types induce us to act or react in a specific way. Some kinds of behaviours in accordance with character types and their strength can give us satisfaction and pleasure. On the other hand, behaviours that are at odds with character types cause us distress or dissatisfaction. The introduced types differ a lot in needs, likes, dislikes, actions, and reactions. Some group of needs are opposite for different character types and induce them to perform opposing behaviours. These differences can be favourable if people understand their diversity and learn to negotiate and cooperate. Understanding, respect, and wise interaction allow people to cooperate and obtain mutual benefits even if a part of their needs are opposing. Man-machine interfaces should also adapt according to the character types of a human user (customer) to make communication more efficient, personalized $[1,10]$, and enjoyable by the user. Tables 1-2 show the most frequently used words, phrases, and forms for all introduced character types and enable a computer system to recognize them by text analysis. Some of the given words and phrases can be characteristic for more than one type of character or can be used in the other meaning or for the other reasons. They can be also extended and weighted according to their frequencies of use.

Dominant type (DOM, opposite to SUB) likes to dominate, lead, guide, control (people and situations), direct, chair, conduct, rule, govern, recommend, suggest, counsel, influence, conquer, restrain, decide, determine, incline, select, choose, speak on behalf of himself and other people, operate, persuade, induce, teach, advise, instruct, program, regulate, designate, appoint, recommend, and 

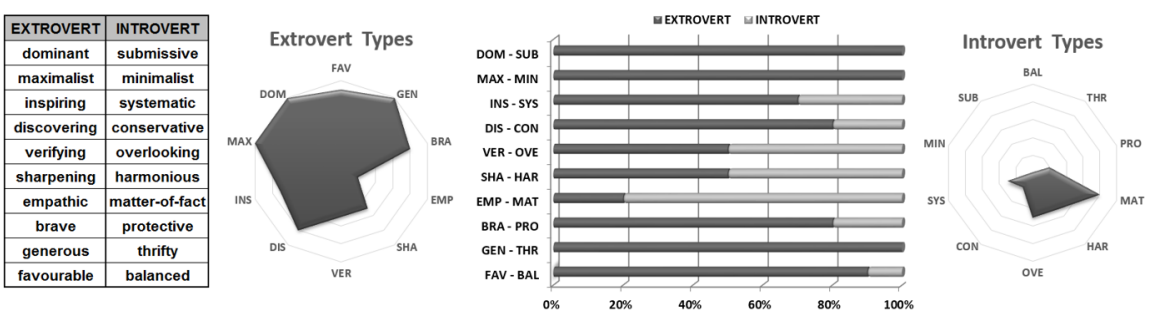

Fig. 1. The comparison of the strength of the character types of a person.

convince somebody of his point of view. He is often a head, boss, manager, or president. He likes to own, have, possess, acquire, purchase, buy, obtain, and master something. He prefers new, original, intact, and untouched things. He likes to be asked for opinion, advice, suggestions, and recommendations, and be thanked for them, bowed, and curtsied. He likes accommodating, submissive, obedient, docile, and yielding people, acceptance of his ideas, decisions, and opinions but not always in partner relationships. He dislikes to be dominated, commanded, managed, determined, restrained, controlled, forced, ordered, steered, manipulated, persuaded, admonished, advised, instructed, depreciated, and humiliated. He likes freedom and independence, so leave him options, alternatives, and ability to choose or decide. He usually dislikes criticism of his opinion, choices, decisions, thoughts, ideas, and proposals. He hates to admit to his failures, mistakes, weaknesses, giving up, loss, inability, incapacity, powerlessness, helplessness etc. You can kindly ask him for various things, actions, and opinions, but do not forget to thank him. Neither ignore nor disregard his opinions, advises, or suggestions. You can lead him using evocative questions and proposals.

Submissive type (SUB, opposite to DOM) seems to be submissive, adjusting, accommodating, obedient, docile, yield, passive, indecisive, conformist, listening, and cooperative. He needs help, support, advice, suggestions, recommendations, assistance, and consultations to act, choice, decide, or operate. $\mathrm{He}$ likes to listen to opinions, analyses, experts, authorities, managers, bosses etc. He does not like to make decision or choices without advice, assistance, and support or take responsibility and control. He does not want to lead, guide, manage, and chair. He avoids or postpones choices and decisions. You can easily cooperate with him by taking control over him and inducing him to accomplish your targets or plans. Give him instructions and clarify your expectations.

Maximalist type (MAX, opposite to MIN) is ambitious, insatiable, unrestrained, excessive, optimistic, demanding, exacting, generalizing, striving to the sublime, unique, extravagant, extreme, and great things, properties, imaginations, actions, feelings etc. He likes to have, get, own, possess, obtain, and win more and more, first positions, something bigger, larger, longer, faster, better, or possibly all, everything, everywhere etc. He looks for something extreme, unique, rare, unusual, enormous, huge, super, great, significant, maximal, and the best. He dislikes restrictions, limitations, reductions, decreases, simplifications, half 
measures, compromises, mediocrity, minor, lesser, small, or insignificant things, goals, aims, targets, actions, features, parameters, experiences, or feelings. He avoids pessimists and people who cut off, discourage him or try to persuade him that his targets are beyond his scope. He likes challenges and to talk about significant plans, visions, concepts, targets, aims, and goals. Help him to overcome limitations and restrictions. You can easily offer him everything that will make him closer reaching his goals and visions. You can also raise the bar for him and give him challenging tasks to solve or manage. Do not give him too many options if you are not ready to give him all of them. Let him compete, rival, vie, emulate, and contend. It strengthens all other types of character and personality.

Minimalist type (MIN, opposite to MAX) seems to be minimizing, passive, with low expectations, and settling for what he already has. He can renounce, withdraw, or pull out when something requires too much effort, or he is pushed to do too many or too difficult things. He has no special or ambitious needs, requirements, or expectations. Almost everything he has is sufficient for him. He is satisfied with standards, and common things, actions, treatment, and features. He likes easy jobs and tasks, so he usually does not take up optional or challenging tasks. Competition or punishment will not motivate him to do something more or better, but you can assign simple tasks to him.

Inspiring type (INS, opposite to SYS) seems to be inspirational, creative, spontaneous, improvising, concocting, unconventional, enigmatic, surprising, inspiring, unpredictable, and sometimes impulsive, hasty, rash, irrational, disorganized, and chaotic. He likes new, different, various, interesting, inspiring, mysterious, fascinating, secretive, funny, artistic, unique, creative things, actions, and features. He looks for unusual arrangements, associations, things, features, actions, reactions, parameters, layouts, relations, feelings, experiences, knowledge, behaviours, ideas, concepts, targets etc. He likes surprises, astonishments, and unexpected things, and behaviours to act differently, intuitively, and creatively. He does not like well-worn phrases, trite words, outlines, rigid rules, plans, models, systematics, established procedures, stiff routines, regulations, categorizations, classifications, and stereotypes. He dislikes common, simple, normal, usual, and ordinary things, features, behaviours, and repetitions of the same operations. Do not cut his ideas or proposals. Let him inspire and positively surprise other people. Try not to limit or restrict him. Use his ideas and talk with him about them. Leave him create or find extraordinary solutions.

Systematic type (SYS, opposite to INS) seems to be systematic, organized, arranging, scheduling, steady, regular, predictable, and schematic. He likes plans, notes, regulations, models, rules, outlines, diagrams, formulas, schemes, recipes, systems, standards, norms, schedules, punctuality, lists, tables, grouping, arrangements, clusterization, classification, typologies, and systematics. $\mathrm{He}$ also likes to sort, order, arrange, organize, systematize, shape, categorize, classify, cluster, group, form a sequence or chronology, enumerate, list, and schedule everything. He operates in order and acts according to prepared schedules, plans, rules, and algorithms, and ticks and marks off the completed tasks. To him, everything should have its right place and time. He enumerates often and 
shows chronological dependencies between things, operations, and actions. He creates models, plans, and strategies for possibly all predictable situations. He dislikes mess, disorder, lack of arrangements or plans. He usually does not like surprises, twists that violate his plans or schedules. When dealing with him, try to be punctual, organized, and precise, and keep things in order and chronology. Map, reproduce, or copy his way of ordering things and enumeration. Try not to change his plans or schedules or give him time to plan again or reschedule.

Table 1. The characteristic words, phrases, and forms for the extrovert types.

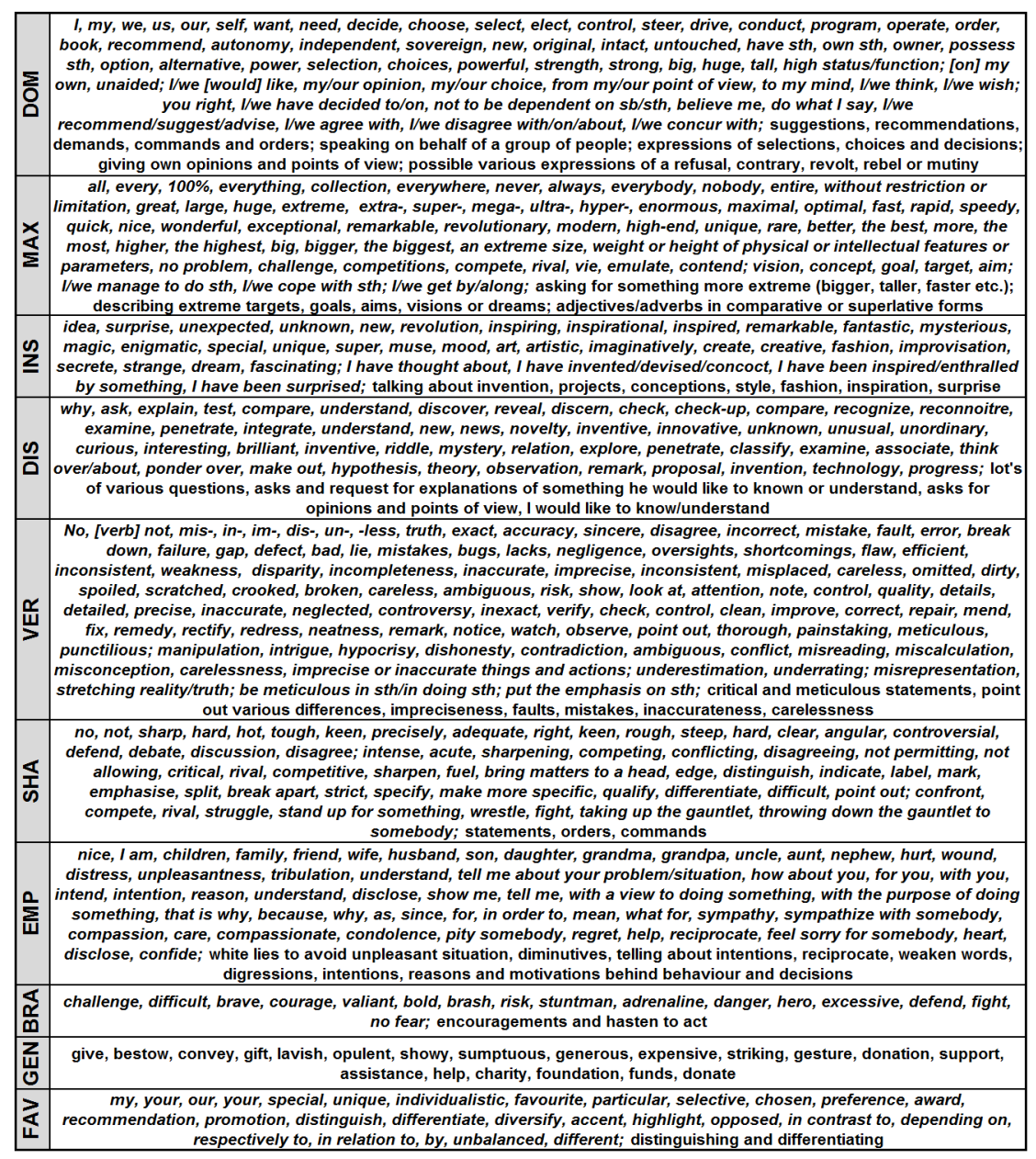

Discovering type (DIS, opposite to CON) seems to be discovering, curious, inquiring, investigating, detective, open-minded, liberal, tolerant, and progressive. He likes to discover, examine, explore, test, check, try, experiment, de- 
compose into prime factors, form various associations and understand unknown and undiscovered things, actions, reactions, behaviours, relations, features, or mysteries. He frequently queries himself and other people, so he likes open questions and discussions. He likes to watch, listen, touch, sniff, and taste various interesting thing in order to discover something new, unknown, unusual, curious, enigmatic, mysterious, obscure, and unusual happenings. He likes news, new hypotheses, technologies, statements, laws, rules, models, principles, theories, inventions, investigations, and their products. He dislikes stereotypes and simple, normal, unusual, common, and ordinary things, features, actions, reactions, rigid rules, plans, procedures, boredom, inactivity, lack of novelty, innovations, and changes, a repetition, a monotony, a humdrum, and a routine. He hates conservatism as well as immutable, primitive, and backward things and views. Try to use or reveal new hypothesis, theories, rules, or principles together with him.

Conservative type (CON, opposite to DIS) seems to be conservative, conventional, traditional, permanent, loyal, sentimental, faithful, stable, unchanging, hermetic, insular, and retaining the old. He likes permanent, immutable, unchanged things and behaviours. He likes conventions, rules, principles, fidelity, tradition, faith, and doctrines. He prefers old, checked, known, proven, well-tried, the same places, time, and people. He usually rejects new ideas, hypothesis, theories, principles, or rules and does not change his mind often. He hardly accepts any progress, changes, or innovations. He does not like revolution or evolution. He prefers solid, fixed, permanent things and behaviours and dislikes mixtures, hybrids, new combinations etc. Do not try to convince him too fast but gradually introduce and explain to him new ideas, hypotheses, and theories. He emphasizes faith, loyalty, and faithfulness.

Verifying type (VER, opposite to OVE) is always meticulous, pedantic, verifying, comparing, differentiating, discriminating, checking, inspecting, monitoring, controlling (quality, compliance), honest, truthful, evaluating, and commenting, looking for details, inconsistency, mistakes, incompatibility, and incoherency. He likes to watch, observe, listen, feel, and smell to compare, distinguish, and find out differences, faults, mistakes, errors, bugs, lacks, contradictions, breakdowns, misplacements, failures, defects, gaps, carelessness, omissions, shortcomings, oversights, negligence, inconsistencies, incoherency, incompatibility, inaccuracy, inexactness, inexactitude, weaknesses, disparity, misreading, miscalculations, misconceptions etc. He pays attention to dirty, spoiled, scratched, crooked, broken, careless, risky, and ambiguous things. He tries to check, point out, verify, control, clean, improve, correct, repair, mend, rectify, remedy, and fix them. He can easy disagree, deny, or oppose. He also likes to detect and uncover lies, manipulation, untruth, and falsehood. He does not like when somebody ignores or disregards his remarks and comments. You do not have to agree with him but take into consideration his remarks, suggestions, notices, critique, and comments. Neither quarrel nor argue with what he has said but thank him for them and ask for more details until he will not finish. Do not underestimate or underrate his notices. Treat them as a kind of help and allow him for notices, remarks, and observations. Weigh your words and choose them carefully. 
Table 2. The characteristic words, phrases, and forms for the introvert types.

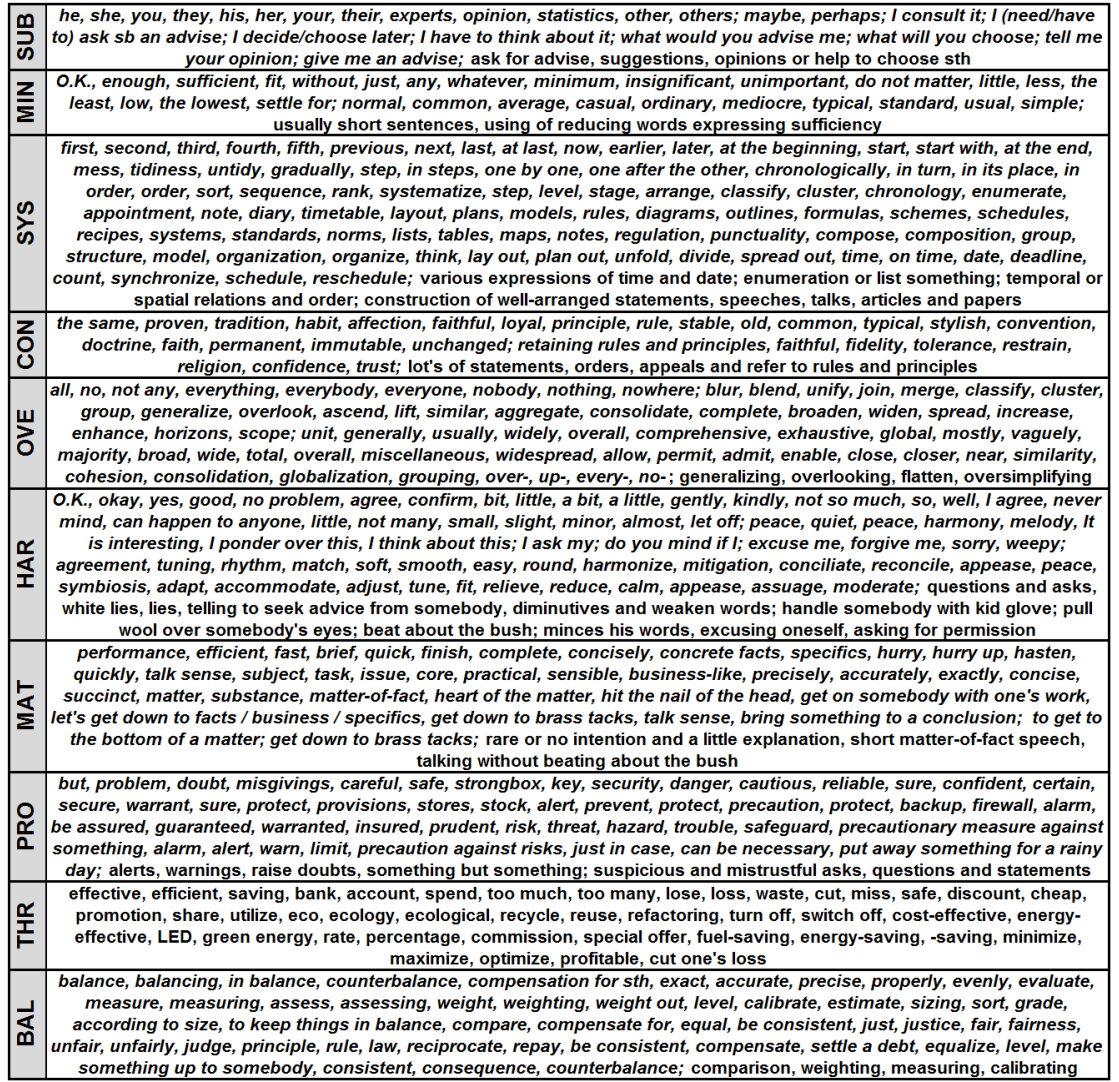

Overlooking type (OVE, opposite to VER) seems to be overlooking, blurring, blending, unifying, joining, merging, generalizing, ascending, lifting, looking for similarities, aggregations, unification, grouping, classifying, clustering, and consolidating. He likes to blur, blend, unify, join, merge, generalize, overlook, ascend, lift, broaden, widen, spread, and widespread. He allows permits, admits, and enables some unimportant or irrelevant mistakes, errors, faults, inconsistency, incompatibility, incoherency etc. He is tolerant and understanding. He usually passes over details, trifles, odds and sods. He does not like narrowing, reducing, or depleting. Assortments, types, sorts, differences, diversities, and discrimination are not as important for him as globalization, generalization, grouping, clusterization, and classification. Try to generalize and show tasks broadly, generally, and in a broad context or scope. Pass over the marginal, trifles and do not be too accurate and meticulous if not necessary.

Sharpening type (SHA, opposite to HAR) is sharp, hard, tough, hot, active, keen, intense, acute, sharpening, competing, conflicting, disagreeing, forbidding, disallowing, critical, rivalling, and competitive. He likes to sharpen, fuel, 
inflame, exacerbate, bring matters to a head, edge, distinguish, indicate, label, mark, emphasize, split, break apart, strict, specify, make more specific, qualify, differentiate, and point out. He also likes to confront, compete, rival, struggle, or stand up for something, wrestle, fight, take up the gauntlet, and throw down the gauntlet to somebody. He dislikes to resign, ease off, give up, withdraw, abandon, dispense, skip, smooth, moderate, and tone down. Try to explain, establish, fix, and arrange everything necessary.

Harmonious type (HAR, opposite to SHA) is harmonious, compliant, agreeable, tuning, avoiding conflicts, quarrels, critics, rows, brawls, fights, and disagreements, prone to compromises, reconciling, non-confrontational, gentle, symbiotic, forgiving, and softening. He likes rhythm, matching, softening, smoothing, rounding, harmony, mitigation, ease, conciliation, and reconciliation of people. He often arbitrates, mediates, alleviate stress and nervous situations, appeases disputes and conflicts, and makes peace with others or symbiosis between things. He can forgive, adapt, accommodate, adjust, tune, fit, and make things together. He relieves, reduces, calms, appeases, assuages, eases, and moderates all conflicting or difficult situations. He opens up very slowly. If you drive or force him to do something, he will lie or keep away from you in future.

Empathic type (EMP, opposite to MAT) seems to be empathic, personal, talkative, compassionate, caring, affectionate, sensitive, tender, emotional, gentle, open, warm, and soothing. He likes to listen to emotional confidences and secretes. He tries to be closer, friendlier, and reducing distance. He likes to personify and embody animals and even things. He reveals himself and expect the same from others. He does not like when somebody hides emotions or is cool, subjective, impersonal, and formal, does not explain his intentions or reasons of doing something, cuts personal reflections or moves immediately to the heart of the matter. Try to understand his intentions and do personal digressions.

Matter-of-fact type (MAT, opposite to EMP) seems to be subjective, businesslike, matter-of-fact, brief, concise, succinct, curt, productive, practical, efficient, focused, cool, impersonal, and often personally self-contained, introvert, and shy. He is focused on subjects and practical aspects. He dislikes uncompleted work and unfinished tasks or examinations. He also likes to finish previous tasks before he starts a new one. He comes straight to the point, gets to the heart of the matter, and hits the nail on the head. He does not like when somebody handles him with kid gloves, pulls wool over his eyes, beats about the bush, or minces his words. He dislikes irrelevant or personal reflections or digressions. He rarely reveals personal reasons, purposes, or intentions. He does not like vague and unsubstantial discussions and conversations. He usually hastens and pushes for concrete facts if somebody is beating about the bush. Talk to him briefly, concisely, in concrete terms, and go straight down to business. Use facts, specifics, and get down to brass tacks. Do not reveal yourself too much or too quickly. Avoid assigning to him next tasks before he finishes the previous ones.

Brave type (BRA, opposite to PRO) seems to be brave, courageous, surpassing, daring, valiant, heroic, bold, brash, and open to risk. He likes adrenaline, danger, hazard, and risk, so often behaves like a stuntman. He likes to take up 
difficult and dangerous challenges and puts out challenges to other people. He is usually skilful, fit, and active. He dislikes timid, fearful, and cowardly people. He avoids too much insurance, protection, and security, because it deprives him of pleasure. He does not like to talk about protection, security, risks, and threads. Allow him surpass and cross borders.

Protective type (PRO, opposite to BRA) seems to be protecting, insuring, ensuring, preventive, careful, restrained, and cautious, questioning, blocking, checking, and controlling safety. He likes guarantee, safeguards, and safe alternatives. He usually warns others against risks, threads, and danger, which he tries to limit by prevention, suitable planning, education, examination, or preparation. He purchases proven and reliable products. He always anticipates, expects risks, danger, troubles, and problems, so he demands guarantee, protection, and insurance. He wants to be prepared and know what to do when difficulties or troubles occur. He has some reserves, provisions, and stores for unexpected situations. He does not like underestimating, ignoring, or disregarding his warnings, rules, steps, plans, prevention, and means of caution, safety, and security. He always has a comprehensive policy, insurance, backups, and safe-locks.

Generous type (GEN, opposite to THR) is generous, lavish, and helpful. He can hardly refrain from giving, waiving, and remitting if he is asked for it. He likes opulent, showy, sumptuous, glamorous parties and receptions and to gratify, share, lend, distribute, donate, sponsor, or give gratuities. He gives back or helps using own and foreign resources. He dislikes storing money, economical solutions, and misers, so he rarely has reserves and savings. He often purchases splendid and opulent but disposable products. He likes spending money and takes loans. You can easily get his help, support, or a loan even without percentage.

Thrifty type (THR, opposite to GEN) seems to be thrifty, economical, optimizing, minimizing, maximizing, and saving. Saving is his way of earning money or supplementing it. He likes to recycle, refactor, and reuse, so he prefers to purchase multiply used things and products. He likes scalable and profitable products. He counts up and sums up possible or predictable profits, percentage, benefits, and advantages in a longer period of time. He avoids or cuts any predictable losses. He dislikes spoilage and throwaway things, wasting time, money, or unused resources, residues, and leftovers. He switches off the light, engines, and other appliance. He turns off the ovens, radios, computers, gas etc. He likes to use any kind of labour-saving, space-saving, fuel-saving, energy-saving, and cost-effective solutions. He likes promotional campaigns and special offers.

Favouring type (FAV, opposite to BAL) is favouring, preferring, biased, opposite, contrasting, advertising, promoting, recommending, selecting, opposing, distinctive, distinguishing, destabilizing, careerist, and tolerant. He does not like levelling, smoothing, equalling, balancing, compensating, ruling, adjusting everything, and comparing only similarities. He prefers special, unique, individualistic, particular, different, and contrasting things, features, and people. He likes to award, favour, promote, differentiate, distinguish, diversify, contrast, highlight, accentuate, select, and choose accordingly to one's abilities, knowl- 
edge, and talents. You can ask him to promote or support you. Try to stand out from other people and show your special features and abilities.

Balancing type (BAL, opposite to FAV) is balancing, equating, comparing, weighing, examining, tuning, measuring, assessing, sizing, levelling, calibrating, equally dividing, and usually striving for some kind of justice, compensation, or fulfilment. He likes to arbitrate, adjudicate, and work out rights. He expects balance, counterbalance, reciprocity, and mutual concessions. He expects compensation and usually justice. He dislikes injustice, imbalance, inequality, detuning, favouritism, biasing, corruption, unjust systems, unbalanced things or judgments, unfair, and inconsistent actions. Keep everything in balance, be fair, just, honest, reciprocating, self-critical, and compensating. Divide exactly, evenly, and equally. Do not promote or favour somebody or something too much without justification and arguments balancing such kind of behaviours.

Needs of intellect and spirit are related to the activities that lead to develop intelligence, knowledge, and express egocentric or non-egocentric attitude [5]. People who actively develop their intellect like to associate interesting facts in various contexts learn and seek for new information channels. They like to increase their possibilities of perception of incoming information. They clarify and expand their vocabulary of terms to increase possibilities to differentiate and discriminate. They try to make their knowledge reliable, coherent, consistent, verified, and well-associated with other facts. They like to receive, acquire, and purchase a variety of information sources. They also want to cooperate with other people who have interesting knowledge, experience, or abilities. They like to read books, magazines, papers, create efficient methods, techniques, algorithms, and solutions, so they often use the following words and phrases: data, information, knowledge, learning, teaching, education, study, research, investigation, school, college, university, technology, magazine, book, newspaper, publication, article, science, scientific, cognitive, think, reason, cause, effect, motive, consider, reconsider, explore, apply, explain, understand, clever, smart, intelligent, intelligence, intellect, associate, associations, relation, relationship, correlation, development, progress, growth, evolution, revolution, transformation, adaptation, searching for, looking for, seek, find out, explain it to me, let me know, definition, accuracy, accurately, precisely, exactly etc. Intelligence increase efficiency and boosts effectiveness. It optimizes behaviours and operations as well. When people cooperate, join, assist, work together, and are not selfish, the cooperation is more efficient. Egocentrism destroys relations, cooperation, and causes competition, rivalry, scrambling, fight for positions, and ineffective use of resources. The development of intelligence/intellect is associated with understanding wide context, relations, correlations, dependencies and needs.

\section{Man-Machine Interaction Taking into Account Needs}

Man-machine interaction can satisfy people if machines will be able to properly react on human needs and find out the answers for them. Machines should be able to automatically recognize and classify human needs even if people do not 
reveal or describe them. Linguistic communication is very natural for people, so it can be used to classify individual human personality in order to adjust machine reactions to it. Using the described personality systematics machines can sum weighted numbers of characteristic words, phrases, and inflection. The measurement of intensities of character types is based on counting characteristic linguistic objects that are weighted by their uniqueness in view of all types (Tab. 3). The presented systematics describes also the recommended treatment of the person of an established type of character. It makes possible to change the machine way of talking, presenting information, or automating correspondence $[2,3,11,12]$. Moreover, the answers for asked questions can take into account also the other recognized needs that were not expressed in given questions. It allows us to construct intelligent and personality sensitive man-machine interfaces that make the interaction between people and machines more human, pleasant, predictable, and friendly. We can even predict the most probable choices and decisions of a customer after gained knowledge about his character types. This knowledge can be used to adapt a way of further conversation and presentation to maximize the positive answer of a customer. Identification of human needs is also indispensable to a development of intelligent systems that are oriented to form the knowledge [5] and raise their intelligence $[13,14]$.

Table 3. Psycho-linguistic analysis of character types.

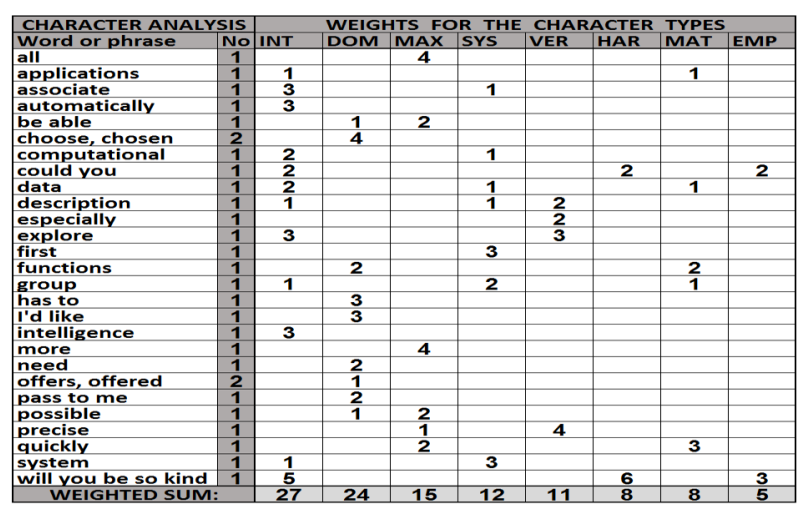

Texts written by people are automatically parsed and analysed taking into account all important linguistic objects and their weights (Tab. 3), e.g.: "I'd like to choose between two or more offers. Will you be so kind and could you pass them to me as quickly as possible? I need precise description of the offered applications, especially about the functions that provide new computational intelligence features. First of all, the chosen system has to be able to associate, explore, and group new data automatically." This text sample is very short but it enables us to gain fundamental knowledge about character types and intelligence of the person that has written it. Table 3 contains the list of the words and phrases that have occurred in the above text and the numbers of their oc- 
currences. Namely, this person is intelligent (INT) and very dominant (DOM) probably is a boss or a head. He is also maximalist (MAX), systematic (SYS), and verifying (VER). Probably he is also a bit harmonious (HAR) and matterof-fact (MAT). About his emphatics (EMP) we cannot be sure, because any word uniquely defines this type and the total weighted sum is not significant.

\section{Conclusion and Final Remarks}

This paper has presented an extended model of psycholinguistic personality systematics that help to automatically classify human personality and recognize individual needs after the simple analysis of text written by an analysed human. The defined groups of needs allow the system to quickly adapt and foresee the other very probable needs, interests, businesses, behaviours, actions, and reactions of the human. The presented way of recognition and classification is automatic and passive, i.e. there is no need to ask a person to analyse or estimate his personality or reveal his or her needs. This kind of passive and automatic recognition of needs can supplement the information of a given person gathered in a traditional way by analysing his action, purchased products etc.

\section{References}

1. Dyche Jill, CRM - relations with customers. Helion, Gliwice, (2002)

2. Horzyk, A., Tadeusiewicz, R.: A Psycholinguistic Model of Man-Machine Interactions Based on Needs of Human Personality. Advances in Intelligent and Soft Computing. Springer, Vol. 59, 55-67 (2009)

3. Horzyk, A., Magierski S., Miklaszewski G.: An Intelligent Internet Shop-Assistant Recognizing a Customer Personality for Improving Man-Machine Interactions. Recent Advances in Intelligent Information Systems, Warsaw, EXIT, 13-26 (2009)

4. Horzyk, A.: Negotiations: The Proven Strategies. Edgard, Warsaw, 1-192 (2012)

5. Horzyk, A.: Artificial Associative Systems and Associative Artificial Intelligence. Exit, 1-280 (2013)

6. C.G. Jung, Psychological Types, The collected works of C.G.Jung, vol. 6, eds. R.F.C. Hull, Princeston University Press (1971)

7. Mirski, A.: Managing Creativity in the Enterprise Culture. Krakow, Wzorek (2013)

8. I.B. Myers, P.B. Myers, Gifts differing: understanding personality type, CA: Davies-Black Publishing, Mountain View (1995)

9. A. Skowron, P. Wasilewski, "Interactive information systems: toward perception based computing." Theor. Comput. Sci., vol. 454, pp. 240-260 (2012)

10. Sac-Tang, S., Esichaikul, V.: Web Personalization Techniques for E-commerce, Active Media Technology, Springer-Verlag, pp. 36-44 (2011)

11. Tadeusiewicz, R.: Speech in Human System Interaction. In: 3rd International Conference on Human System Interaction, Rzeszow (2010)

12. Tadeusiewicz, R.: New Trends in Neurocybernetics. Computer Methods in Materials Science. Vol. 1, 1-7 (2010)

13. Tadeusiewicz, R.: Introduction to Intelligent Systems, In: The Industrial Electronics Handbook - Intelligent Systems, Boca Raton, CRC Press, 1-12 (2011)

14. Tadeusiewicz, R.: Place and Role of Intelligent Systems in Computer Science. Computer Methods in Materials Science. Vol. 10, No. 4, 193-206 (2010) 